\title{
IL-1 $\beta$ produced by aggressive breast cancer cells is one of the factors that dictate their interactions with mesenchymal stem cells through chemokine production
}

\author{
Pauline Escobar $2,{ }^{*}$, Céline Bouclier ${ }^{1,2, *}$, Julien Serret ${ }^{2}$, Ivan Bièche ${ }^{3}$, Madly Brigitte ${ }^{2}$, \\ Andres Caicedo², Elodie Sanchez ${ }^{2}$, Sophie Vacher ${ }^{3}$, Marie-Luce Vignais ${ }^{2}$, Philippe \\ Bourin $^{4,5}$, David Geneviève ${ }^{2}$, Franck Molina ${ }^{1}$, Christian Jorgensen ${ }^{2}$, Gwendal \\ Lazennec ${ }^{1}$ \\ ${ }^{1}$ CNRS, SYS2DIAG, Cap Delta, Montpellier, F-34184, France \\ ${ }^{2}$ INSERM, U844, U1183, Montpellier, F-34091, France \\ ${ }^{3}$ Institut Curie, Unité de Pharmacogénomique, Département de Génétique, Paris, 75248, France \\ ${ }^{4}$ Univercell Biosolutions, Pierre Potier, Toulouse, F-31106, France \\ ${ }^{5}$ CSA21, Toulouse, F-31100, France \\ *These authors have contributed equally to this work \\ Correspondence to: \\ Gwendal Lazennec, e-mail: gwendal.lazennec@sys2diag.cnrs.fr \\ Keywords: breast, cancer, mesenchymal stem cells, IL-1 beta, chemokines \\ Received: March 16, $2015 \quad$ Accepted: July 22, $2015 \quad$ Published: August 04, 2015
}

\section{ABSTRACT}

The aim of this work was to understand whether the nature of breast cancer cells could modify the nature of the dialog of mesenchymal stem cells (MSCs) with cancer cells. By treating MSCs with the conditioned medium of metastatic Estrogenreceptor (ER)-negative MDA-MB-231, or non-metastatic ER-positive MCF-7 breast cancer cells, we observed that a number of chemokines were produced at higher levels by MSCs treated with MDA-MB-231 conditioned medium (CM). MDA-MB-231 cells were able to induce NF-KB signaling in MSC cells. This was shown by the use of a NF-kB chemical inhibitor or an IKB dominant negative mutant, nuclear translocation of p65 and induction of NF-KB signature. Our results suggest that MDA-MB-231 cells exert their effects on MSCs through the secretion of IL-1 $\beta$, that activates MSCs and induces the same chemokines as the MDA-MB-231CM. In addition, inhibition of IL-1 $\beta$ secretion in the MDA-MB-231 cells reduces the induced production of a panel of chemokines by MSCs, as well the motility of MDA-MB-231 cells. Our data suggest that aggressive breast cancer cells secrete IL-1 $\beta$, which increases the production of chemokines by MSCs.

\section{INTRODUCTION}

If cancer cells possess an intrinsic ability to grow and disseminate, increasing evidence suggests, that proliferative and invasive properties of cancer cells are acquired through exposure to paracrine signals that they receive from the surrounding microenvironment $[1,2]$. In the stromal compartment, the role of cells such as CAFs (carcinoma associated fibroblasts) has been highlighted $[3,4]$. Interestingly, mesenchymal stem cells (MSC) have been recently described as another source of CAFs in addition to fibroblasts [5-7]. MSCs have been isolated from bone marrow (BM), adipose tissue, peripheral blood, fetal liver, lung, amniotic fluid, chorionic villi of the placenta, and umbilical cord blood [4]. MSCs are capable of self-renewal and differentiation into several cell types such as chondrocytes, adipocytes, osteocytes and myocytes. The immuno-suppressive properties of MSCs have been in particular clinically exploited for graft-versus-host and autoimmune diseases [8].

Recent evidence suggests that MSCs could stimulate the carcinogenesis and that they could migrate toward primary tumors and metastatic sites [4, 9-12]. However, the potential pro- or anti-tumoral action of MSCs remains controversial as some studies indicate that immune or angiogenic properties of MSCs could enhance tumor growth or metastasis [4, 13-15], whereas others have shown either that MSCs protect against cancer evolution 
and induce tumor growth inhibition or have no effect [4, 16-19].

The microenvironment of breast cancer is characterized by the dialog of cancer cells with endothelial cells, fibroblasts, immune infiltrating cells and in particular tumor-associated macrophages (TAMs), which promote tumor progression by stimulating angiogenesis and inducing tumor cell invasion and metastasis [20]. Among the possible mediators of cell interactions, chemokines appear essential for the communication of tumor cells with the microenvironment [21-26]. Chemokines were originally identified as potent attractants for leukocytes such as neutrophils and monocytes, and were generally regarded as mediators of acute and chronic inflammation (inflammatory chemokines) [21]. More recently, chemokines and their receptors have been identified as actors promoting the initiation or progression of cancers [21, 22, 27-29]. Previous studies have also shown that chemokines are involved in the dialog between MSCs and cancer cells or other cells of tumor microenvironment as they can be produced by these different types of cells and change the localization and the properties of MSCs. Indeed, cancer cells as well as cells of the tumor microenvironment such as macrophages can increase the motility of MSCs through chemokine production and, on the other hand, MSCs can produce chemokines which increases cancer cell metastasis [9, 13, 30-35].

The complex dialog between MSCs and cancer cells is certainly critical for the outcome of tumor development. We hypothesized that the reported controversial effects of MSCs could be dependent on the specific properties displayed by different cancer cell subsets. We thus compared the effects of different types of breast cancer cells on MSCs to evaluate whether metastatic - ER-negative or non-metastatic - ER-positive breast cancer cells could differentially alter MSCs in terms of chemokine secretion. We found that contrary to non-metastatic breast cancer cell lines, metastatic breast cancer cells have the ability to induce release by MSCs of a number of chemokines. This occurs through activation of the NF- $\kappa$ B pathway in MSCs and suggests a possible autocrine loop involving IL-1 $\beta$. Altogether, these data suggest that metastatic breast cancer cells secrete IL-1 $\beta$, and maybe other unidentified factors, to promote the release of chemokines by MSCs, which in turn could enhance the invasion properties of cancer cells.

\section{RESULTS}

\section{Aggressiveness of breast cancer cells stimulates the repertoire of chemokines produced by MSCs}

As MSCs have been shown to play both pro- and anti-tumoral roles, we hypothesized that the nature of breast cancer cells could change the nature of the dialog of cancer cells with MSCs and in particular the expression of chemokines produced by MSCs. To test this hypothesis, we cultured MSCs in the absence or the presence of conditioned medium (CM) from the metastatic MDAMB-231 and the non-metastatic MCF-7 breast cancer cell lines. A screen of chemokine RNA levels in MSCs was then performed (Figure 1). We observed that the expression of a number of chemokines was increased in MSCs treated with MDA-MB-231 CM, whereas their expression was not modified by the MCF-7 CM. This increase occurred for the chemokines CXCL1, 2, 3, 5, 6, 8 and CCL2, 3, 5 and 20 (Figure 1). In the meantime, the expression of chemokines CXCL4, CXCL12 and CCL8 was not significantly modified by MDA-MB-231 and MCF-7 CM (Figure 1).

In order to determine the kinetics of regulation of chemokine expression in MSCs, we focused on 7 chemokines highly induced by the MDA-MB-231 CM (CXCL1, 3, 5, 6, 8, CCL2, 5) and on one not regulated (CXCL4). We analyzed their expression at 1, 6 and 24 $\mathrm{h}$ of treatment with conditioned medium. Interestingly, these chemokines displayed distinct patterns of regulation (Supplementary Figure S1). CXCL1 was rapidly induced by the MDA-MB-231 CM and this induction remained strong at $24 \mathrm{~h}$, whereas the levels of CXCL5, CXCL6 and CXCL8 increased progressively with a maximum at $24 \mathrm{~h}$. Other chemokines such as CCL5, CCL2 and CXCL3 displayed a maximal induction at $6 \mathrm{~h}$. In order to confirm the induction of these chemokines at the protein level, we measured the secretion of the CCL5 and CXCL6 chemokines by MSCs after stimulation with the MCF-7 or MDA-MB-231 conditioned media (Supplementary Figure S2). We observed that MDA-MB-231 CM could greatly enhance the accumulation of both CCL5 and CXCL6 produced by MSCs in the medium compared to non-stimulated MSCs or MSCs treated with MCF-7 CM.

To further establish that the differential regulation of chemokines in MSCs by MDA-MB-231 and MCF-7 was linked to the metastatic and non-metastatic character of the cell lines, we tested the effects of the MDA-MB-436 (metastatic) and BT-474 (non-metastatic) cells in the same conditions at $24 \mathrm{~h}$ (Supplementary Figure S3). The MDAMB-436 CM was able to induce the same chemokines as the MDA-MB-231 CM in MSCs, whereas MCF-7 and BT-474 CM had no significant effect, confirming the hypothesis that metastatic breast cancer cells have a unique ability to increase chemokine levels in MSCs.

\section{MDA-MB-231 cell conditioned medium increases NF- $\kappa B$ signaling}

We explored the mechanisms accounting for chemokine expression in MSCs by testing whether MDAMB-231 could induce in MSCs the NF- $\mathrm{KB}$ signaling, a known regulator of the expression of many chemokines. We treated MSCs with the NF- $\kappa B$ inhibitor Bay11-7085. Co-treatment with Bay11-7085 completely abolished the induction by MDA-MB-231 CM of all chemokines 
Control

MDA-MB $231 \mathrm{CM}$

MCF7 CM

CXCL1

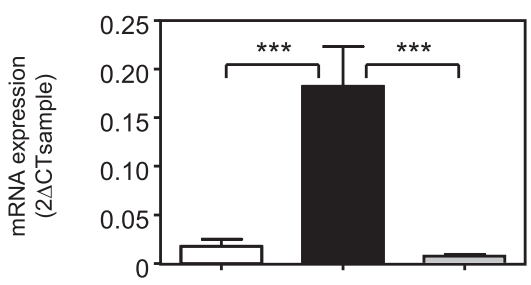

CXCL4

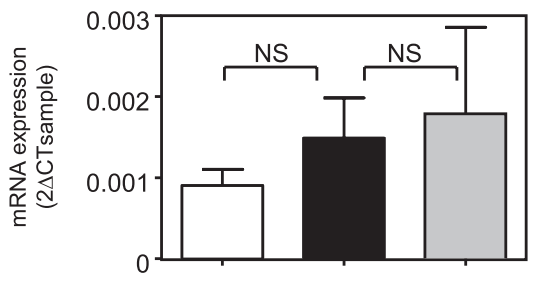

CXCL8

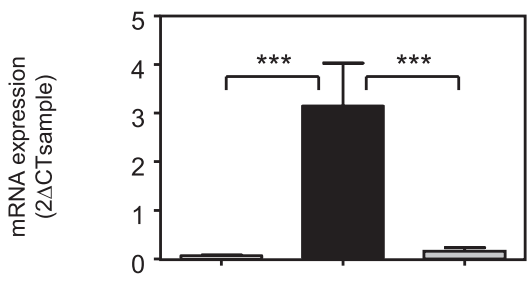

CCL2

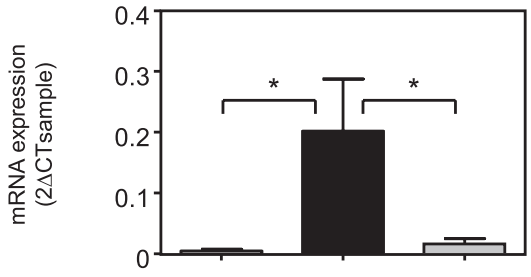

CCL8

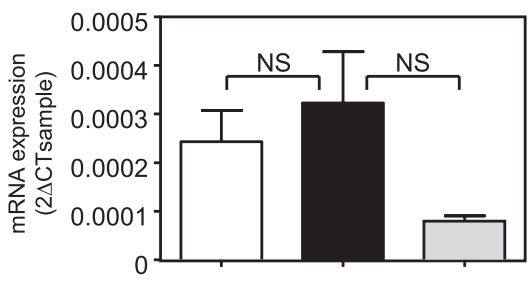

CXCL2

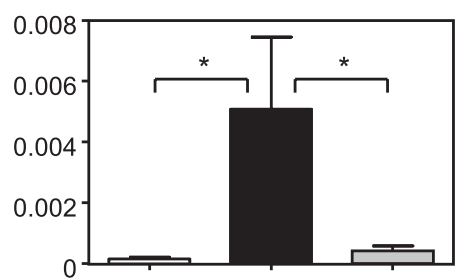

CXCL5

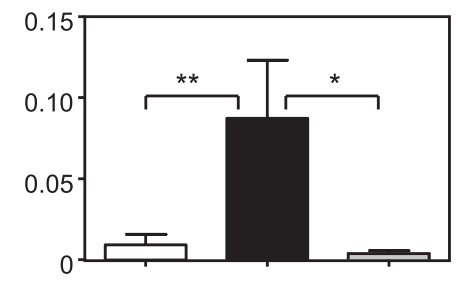

CXCL12

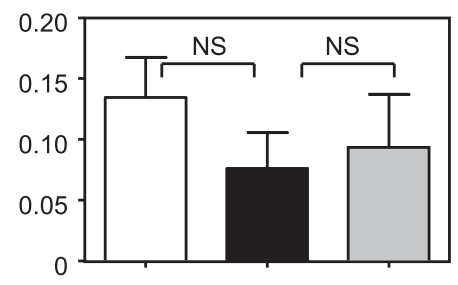

CCL3

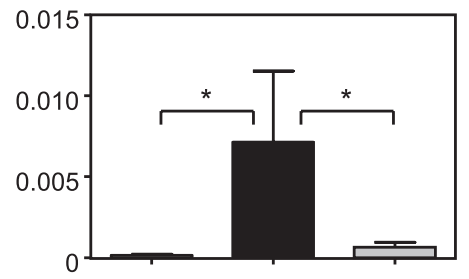

CCL20

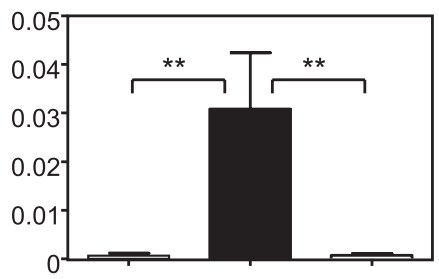

CXCL3

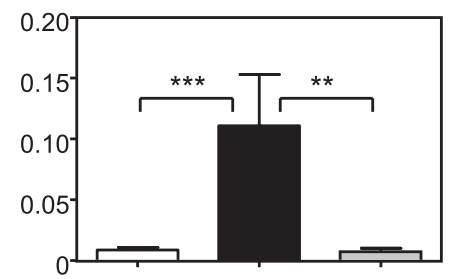

CXCL6

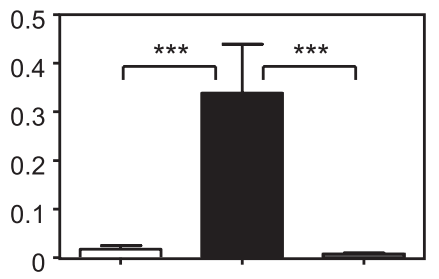

Figure 1: The expression of a number of chemokines is induced in MSCs treated with metastatic cancer cell conditioned medium. MSCs were treated for $24 \mathrm{~h}$ with control non-conditioned medium (Control), conditioned medium from metastatic (MDA-MB-231) or non-metastatic (MCF-7) cancer cells. RNA expression was quantified by real-time PCR and expressed as $2^{-\Delta C T s a m p l e}$ (See Materials and Methods). The graphs correspond to the mean \pm SEM of 6 independents experiments using 5 distinct MSC donors. Measurements of chemokine levels of MSCs treated with MDA-MB-231 CM were compared to the ones of MCF-7 or control medium by unpaired Student's $t$ test. NS: non significant, ${ }^{*} p<0.05, * * p<0.01, * * * p<0.001$. 
tested, except CXCL4 that is not significantly regulated by MDA-MB-231 CM (Figure 2). We confirmed this result by another approach, using a dominant negative form of I $\kappa$ B (I $\mathrm{B}$ DN) [36]. Expression of I $\mathrm{B}$ DN in MSC cells prevented the induction of chemokines by the conditioned medium of MDA-MB-231 cells (Supplementary Figure S4), further highlighting the role of NF- $\kappa B$ pathway. Next, we analyzed the expression of a collection of genes known to be regulated by the $\mathrm{NF}-\kappa \mathrm{B}$ pathway (Figure 3 ). We observed that many of these NF- $\kappa \mathrm{B}$ target genes, including TNF- $\alpha$, IL-1 $\alpha$, IL-1 $\beta$, IL-6, CSF-1, GM-CSF, TNFAIP3, E-selectin, ICAM, VCAM and BCL2A1, were induced by MDA-MB-231 CM but not by MCF-7 CM, (Figure 3). VEGF, TRAILR2, MMP2 and MMP11 were not regulated
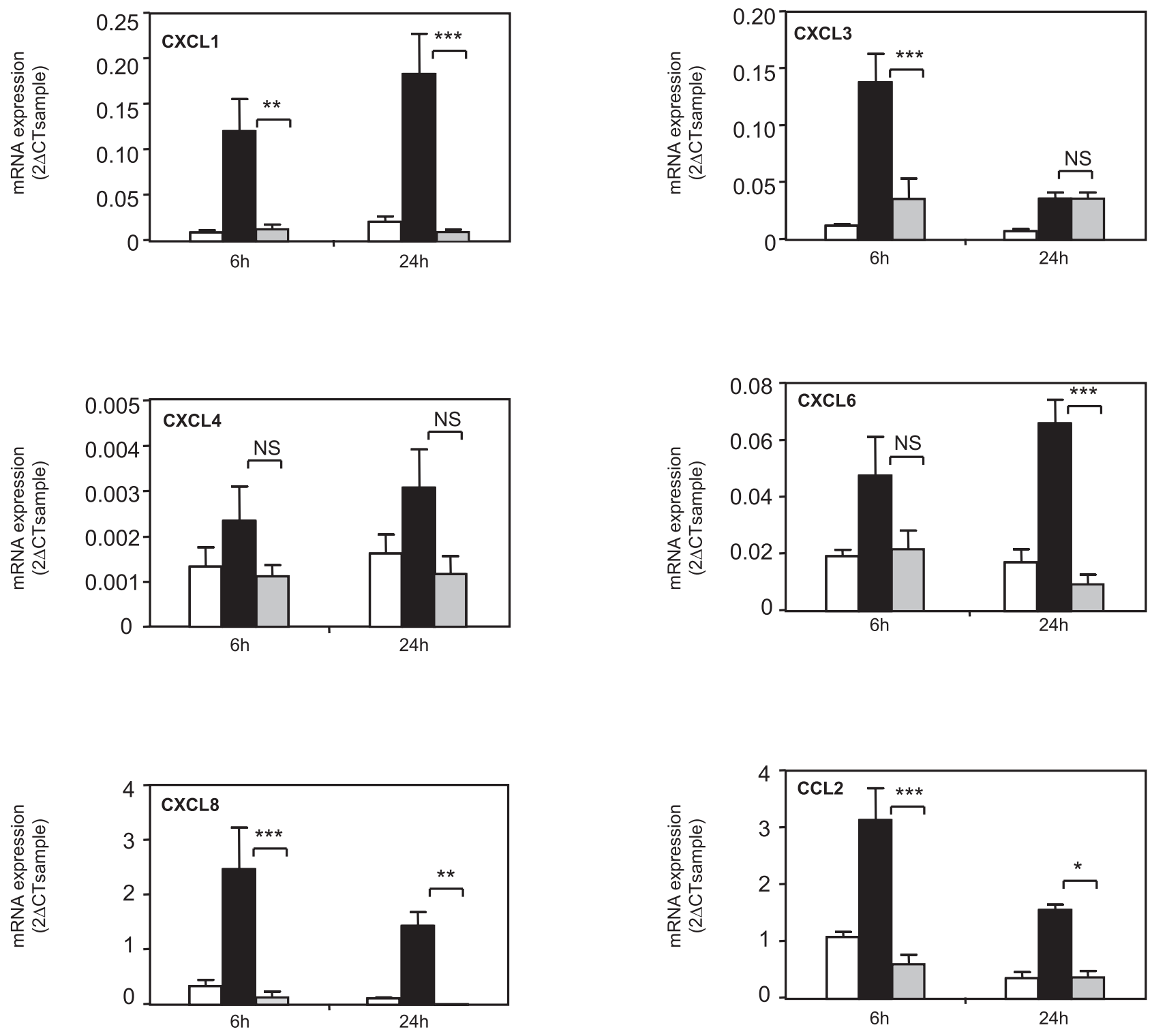

Figure 2: NF-кB pathway is involved in chemokine regulation in MSCs. MSCs were treated for 6 or $24 \mathrm{~h}$ with conditioned medium from MDA-MB-231 cancer cells in the presence or not of BAY11-7085 (10 $\mu \mathrm{M})$. RNA expression was quantified by real-time PCR. The graphs represent the mean \pm SEM of 3 independent experiments. The levels of chemokine expression in MSCs treated with MDA-MB-231 or with MDA-MB-231+BAY were compared for $6 \mathrm{~h}$ and $24 \mathrm{~h}$ by unpaired Student's $t$ test. NS: non significant, ${ }^{*} p<0.05$, $* * p<0.01, * * * p<0.001$. 
MDA-MB-231

MCF-7
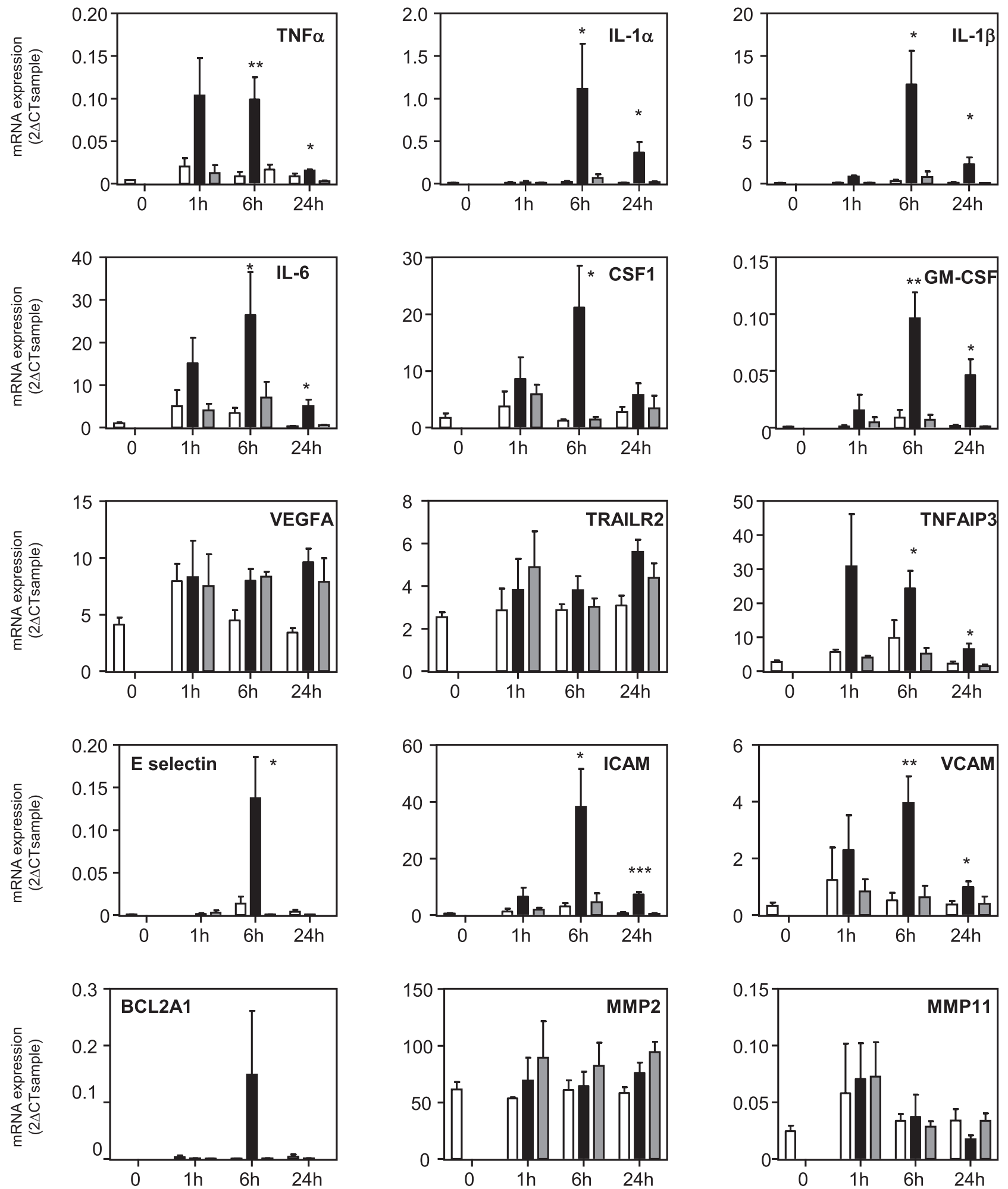

Figure 3: Gene expression profile of NF-kB pathway in MSCs treated with cancer cell conditioned media. MSCs were treated $0,1 \mathrm{~h}, 4 \mathrm{~h}$ or $24 \mathrm{~h}$ with control non conditioned medium (C), conditioned medium from MDA-MB-231 or MCF-7 cancer cells. RNA expression was quantified by real-time PCR. The graphs correspond to the mean of 3 independent experiments. The levels of gene expression in MSCs treated with MDA-MB-231 was compared to the one of control medium by unpaired Student's $t$ test. NS: non significant, $* p<0.05, * * p<0.01, * * * p<0.001$. 
by the cancer cell conditioned medium. To further demonstrate the involvement of $\mathrm{NF}-\kappa \mathrm{B}$ signaling, we looked at the nuclear localization of p65 (Supplementary Figure S5A). Whereas the control MSC nuclei were mostly devoid of p65, the TNF $\alpha$ treatment of MSCs triggered, as expected a strong nuclear localization of p65, which is a hallmark of NF- $\kappa \mathrm{B}$ activation (Supplementary Figure S5A). Note worthily, incubation of the MSCs with the MDA-MB-231 CM led to p65 nuclear relocalization (albeit with various efficacies), in 33\% of the cells in contrast to the MCF-7 CM that only raised the percentage of MSCs positive for nuclear p65 from 2\% (control cells) to $5 \%$ (Supplementary Figure S5B). These results were confirmed by analysis of nuclear p 65 content by western blot, showing also accumulation of p65 upon treatment with the MDA-MB-231 CM (Supplementary Figure S5C).

\section{IL-1 $\beta$ is one of the factors increasing chemokine expression in MSCs}

Based on these results, we wanted to identify the factors released by MDA-MB-231 cells that could activate the NF- $\mathrm{B}$ pathway and increase the production of chemokines by MSCs. We measured in the supernatant of metastatic and non-metastatic breast cancer cells the production of IL-1 $\beta$, a known inducer of NF- $\kappa$ B pathway and chemokine expression (Supplementary Figure S6). We report that MDA-MB-231 and MDA-MB-436 cells were secreting IL-1 $\beta$, whereas the non-metastatic MCF7 and BT-474 cells did not. To understand this cross-talk better, we treated MSCs with IL-1 $\beta$ and observed that the same chemokines that were induced by MDA-MB-231 $\mathrm{CM}$ were also increased by IL-1 $\beta$ (Figure 4 ). This was also confirmed in terms of chemokines CXCL1, CXCL6, CXCL8, CCL2, and CCL5 protein secretion in the medium by MSCs upon IL-1 $\beta$ stimulation (Supplementary Figure S7). These data strongly suggest that the IL-1 $\beta$ produced by MDA-MB-231 cells is one of the factors involved in the increased production of chemokines by MSCs after stimulation by the MDA-MB-231 cells. Moreover, the conditioned medium from MCF-7 cells transfected with hIL-1 $\beta$ cDNA was able to mimic the induction of the chemokines in MSCs observed with conditioned medium from MDA-MB-231 cells, inducing the exact same chemokines (Supplementary Figure S8). Indeed, chemokines whose expression is induced in MSCs by MDA-MB-231 conditioned medium (CXCL1, CXCL2, CXCL3, CXCL5, CXCL6, CXCL8, CCL2, CCL5, CCL20) were also increased by the conditioned medium of MCF-7 cells transfected with IL-1 $\beta$. On the other hand, chemokines such as CXCL4 and CXCL12, which were not regulated by MDA-MB-231 conditioned medium, were also not altered by MCF-7-IL1 $\beta$ conditioned medium. To further confirm this hypothesis, we silenced IL-1 $\beta$ expression in MDA-MB-231 cells by a shRNA approach, by generating a pool of MDA-MB-231-shIL-1 $\beta$ cells. We could reduce the secretion of IL- $1 \beta$ by MDA-MB-231 cells by about $90 \%$ (Figure $5 \mathrm{~A}$ ). We used the conditioned media from MDA-MB-231 and MDA-MB-231-shIL-1 $\beta$ cells to treat MSC cells overnight. After replacement with fresh medium, cells were grown for $24 \mathrm{~h}$ and conditioned medium retrieved. We then focused on the secretion levels of CXCL1, CXCL6 or CXCL8 by MSCs that had been stimulated or not with conditioned medium from MDAMB-231 and MDA-MB-231-shIL-1 $\beta$ cells (Figure 5B). Indeed, these chemokines are known to stimulate breast cancer metastasis [23]. We observed that MSCs that had been stimulated with conditioned medium from MDAMB-231-shIL-1 $\beta$ were less efficient to produce the three chemokines, suggesting that the secretion of Il-1 $\beta$ by MDA-MB-231 cells was one of the factors responsible for the induction of chemokines in MSC cells, without excluding the role of other factors in this induction. Similar results could be obtained at the RNA level (Supplementary Figure S9). Moreover, silencing of IL- $1 \beta$ decreased some $\mathrm{NF}-\kappa \mathrm{B}$ target genes such as TNF $\alpha, \mathrm{CSCF}-1, \mathrm{VCAM}$ or IL-6, but not IL-1 $\alpha$, ICAM and BCL2A1 (Supplementary Figure S10), suggesting a positive control of IL-1 $\beta$ on NF$\kappa \mathrm{B}$ pathway.

Thus, we hypothesized that a "vicious" circle could take place when MSCs and MDA-MB-231 dialog together: MDA-MB-231 cells secrete IL-1 $\beta$ that induces the production of chemokines by MSCs. These chemokines in return alter MDA-MB-231 behavior and in particular stimulate their invasive properties. To test this hypothesis, we used the conditioned media from MSCs that had been stimulated by the MDA-MB-231 or the MDA-MB-231-shIL-1 $\beta$ cells (Figure 5B) and determined whether they could increase the motility of MDA-MB-231 cells in a wound healing assay (Figure 5C, left panel). We observed that MDA-MB-231 cells had a reduced motility in the presence of medium from MSCs cells that had been in contact with MDA-MB-231-shIL-1 $\beta$ cells compared to the medium of MSCs cells that had been in contact with wild-type MDA-MB-231 cells (Figure 5C, right panel).

These data lead us to propose a scheme in which metastatic breast cancer cells can stimulate their microenvironment and in particular MSCs, to produce IL-1 $\beta$ and presumably other undefined factors, activate

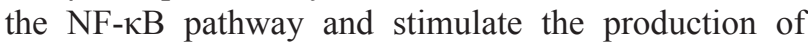
chemokines by MSCs, which in turn will increase the aggressiveness of the breast cancer cells (Figure 6).

\section{DISCUSSION}

The recent discovery of the involvement of MSCs in tumor development has raised a number of questions concerning their contribution to tumor progression [4]. Several studies have shown in particular that MSCs could display a tropism for primary tumor sites as well as sites of metastasis [4, 9, 10, 37]. These migrating MSCs constitute a novel source of CAFs in the tumor, as several studies 

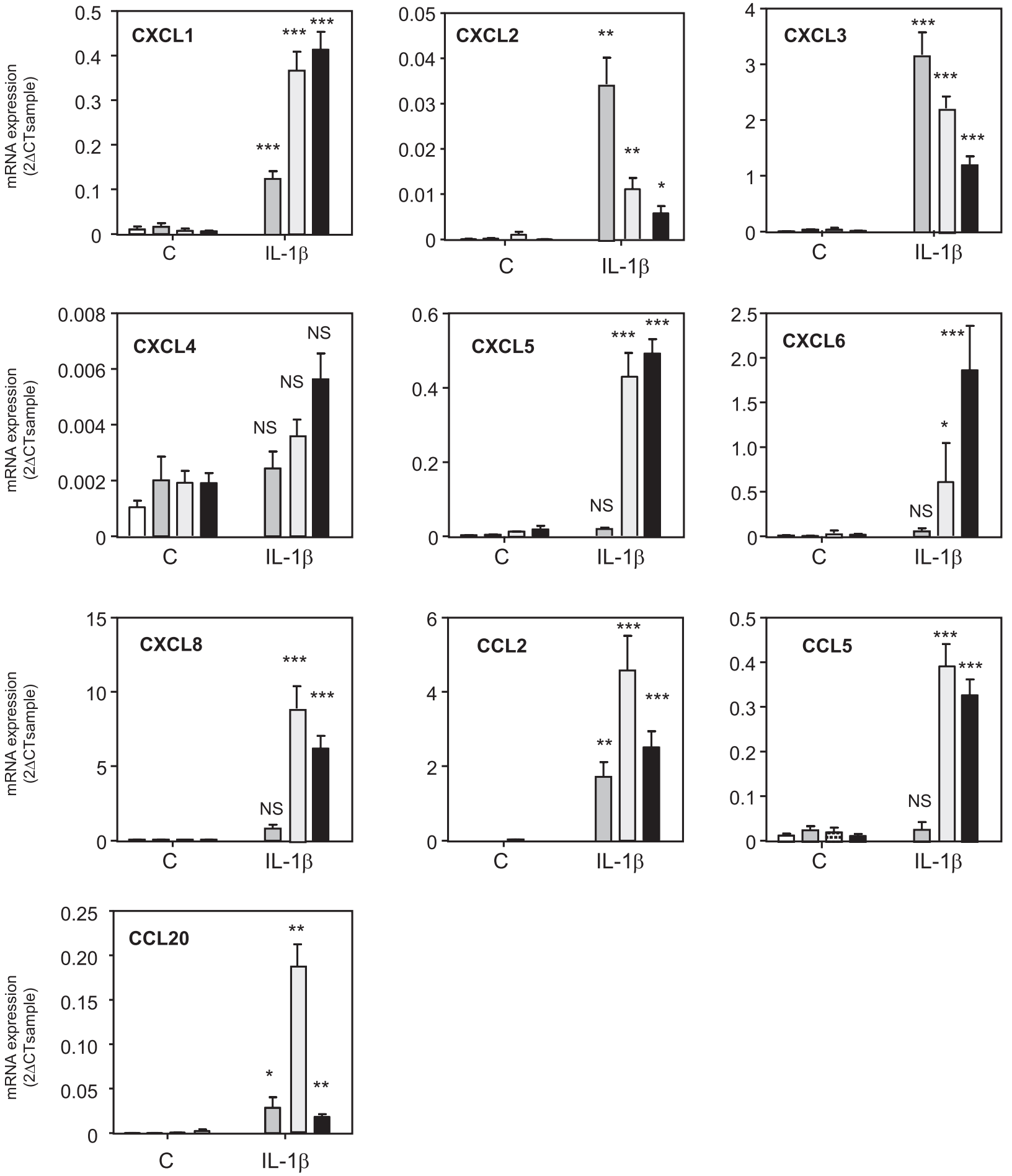

Figure 4: Treatment of MSCs cells with IL-1 $\beta$ induces the same pattern of expression of chemokines. MSCs were treated for $0,1,6$ or $24 \mathrm{~h}$ with $1 \mathrm{ng} / \mathrm{ml}$ of recombinant IL-1 $\beta$. RNA expression was quantified by real time PCR. The graphs correspond to the mean \pm SD of 3 experiments. The kinetics of chemokine expression in control or IL-1 $\beta$ treated MSCs were compared for each time by unpaired Student's $t$ test. NS: non significant, ${ }^{*} p<0.05, * * p<0.01, * * * p<0.001$. 
A
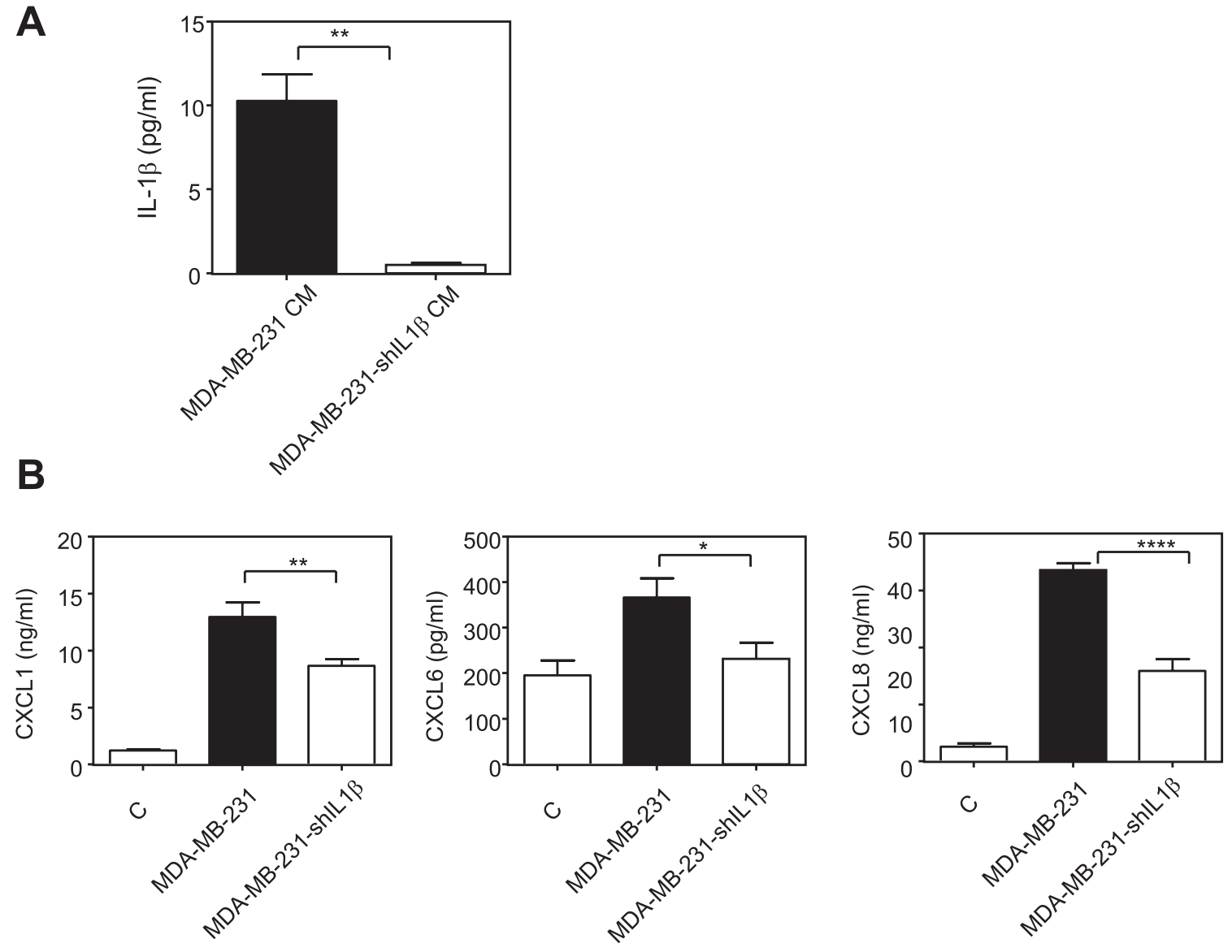

C
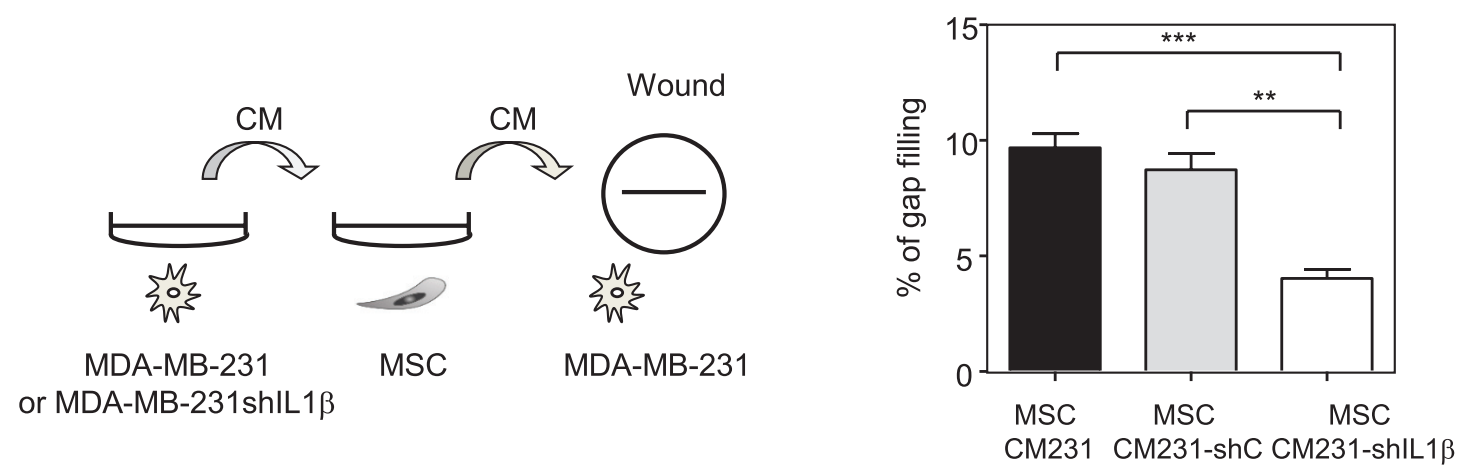

Figure 5: Inhibition of IL-1 $\beta$ production by MDA-MB-231 cells reduces the production of chemokines by MSCs in the presence of MDA-MB-231 conditioned medium. A. MDA-MB-231 cells were stably transfected with empty PLKO1 vector (MDA-MB-231) or a construct against IL-1 $\beta$ (MDA-MB-231-shIL1 $\beta$ ). The secretion of IL-1 $\beta$ MDA-MB-231 or MDA-MB-231-shIL1 $\beta$ was measured by ELISA. The graphs correspond to the mean \pm SEM of 3 experiments. B. MSC cells were treated for $24 \mathrm{~h}$ with control non conditioned medium (C) conditioned medium from MDA-MB-231 transfected with empty PLKO-1 vector (MDA-MB-231) or MDA-MB231-shIL1 $\beta$ cancer cells. The medium was then replaced with fresh one and collected after $24 \mathrm{~h}$ for ELISA assay. The levels of CXCL1, CXCL6 and CXCL8 in MSCs were measured by ELISA. Results represent the mean \pm SEM of 3 independent experiments. C. The medium collected from MSCs treated with the conditioned medium control MDA-MB-231 (MSC CM231) or with MDA-MB-231transfected with sh-scramble (MSC CM231 - shC) or with MDA-MB-231-shIL1 $\beta$ (MSC CM231- shIL1 $\beta$ ) in experiment B was used to treat overnight MDA-MB-231 cells. The next day, a wound was created in each well and the motility of MDA-MB-231 cells was measured by wound healing after $6 \mathrm{~h}$. Left panel represents the scheme of the experiment. Results are expressed as $\%$ of gap filling and represent the mean \pm SEM of 3 independent experiments. 


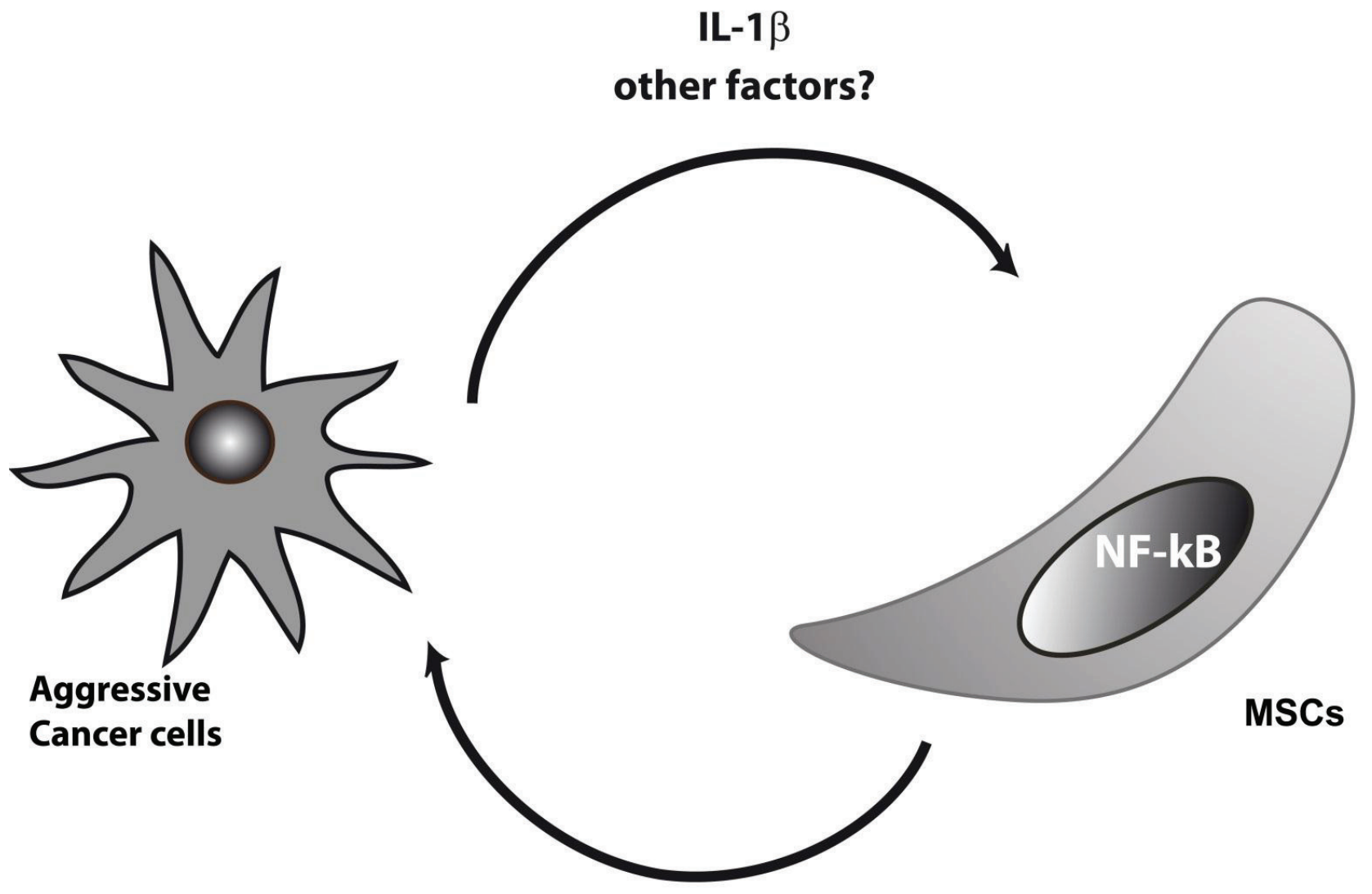

\section{Chemokines}

Figure 6: Model of dialog of aggressive cancer cells with MSCs. Aggressive breast cancer cells secreted IL-1 $\beta$ or other factors that remain to be discovered that activate NF-kB pathway in MSCs. Triggering of NF-kB will enhance the production of chemokines by MSCs, which in turn increase the invasive properties of cancer cells.

have shown that MSCs could be converted in CAFs upon contact with cancer cells [5,38]. Quante et al. have observed that at least $20 \%$ of CAFs isolated from a mouse model of inflammation-induced gastric cancer originate from BM-MSCs [6]. In the same line, using syngenic models of breast and ovarian cancer, another study has also shown that CAFs present in these tumors originated mainly from BM-MSCs [7]. Once present in the tumor, MSCs can affect or not tumor growth or metastasis, either positively or negatively $[4,13,16,39]$. This apparent contradiction led us to hypothesize that the type of cancer cells used in these studies could be responsible for the diverse effects of MSCs on tumor growth and metastasis. In particular, the metastatic status of breast cancer cells or their ER status could be one of the primary features of cancer cells, which could change the interaction of the cancer cells with the tumor microenvironment components such as MSCs and in turn either promote or inhibit cancer progression.

As increasing evidences suggest that chemokines are essential mediators of the dialog between tumor cells and their microenvironment, we explored the effects of cancer cells on chemokine production by MSCs. MSCs express a number of chemokines and chemokine receptors [40, 41].
So, we tested whether MSCs could differentially produce chemokines depending on their interaction with metastatic MDA-MB-231 or non-metastatic MCF-7 breast cancer cells. It should be mentioned in the case of the breast cancer cell lines used in this study, the distinction could also be between Estrogen Receptor alpha (ER $\alpha)$-negative (MDA-MB-231 and MDA-MB-436) and ER $\alpha$-positive (MCF-7, BT-474) breast cancer cells and also on the basis of Epithelial Mesenchymal Transition (EMT), with MDAMB-231 and MDA-MB-436 cells which have undergone EMT. Interestingly, a number of chemokines displayed a strongly induced expression when MSCs were treated with the conditioned medium from the MDA-MB-231 cells, but not with that from the MCF-7 cells. This is in particular the case of CXCL1, 2, 3, 5, 6, 8, CCL2, 3, 5, and 20. This differential regulation of chemokine expression upon treatment of MSCs with conditioned medium from MDA-MB-231 or MCF-7 cells was specific of a subset of chemokines, as other chemokines such as CXCL4, CXCL12 and CCL8 were not regulated by both cell lines (Figure 1B, 1C). Among the chemokines differentially affected by MDA-MB-231 and MCF-7 CM, CCL5 has previously been shown to be induced in MSCs stimulated 
by cancer cells [13]. Other studies have also reported that the CXCL10 expression is increased in MSCs upon release by cancer cells of Hypoxia-Inducible Factors [35]. Interestingly, CCL5 has also been reported to be produced at higher levels by MSCs upon stimulation by CXCL8, CCL 2 and CCL 5 secreted by macrophages [30]. Moreover, we report that the chemokines increased by MDA-MB-231 were induced in a similar manner by another metastatic breast cancer cell line (MDA-MB-436), but not by the nonmetastatic breast cancer cell line BT-474.

To better understand the mechanisms underlying chemokine regulation in MSCs, we tested whether metastatic cancer cells could increase the activity of the $\mathrm{NF}-\kappa \mathrm{B}$ pathway, a major regulator of the expression of a number of chemokines. Treatment of MSCs with the NF$\kappa \mathrm{B}$ inhibitor BAY 11-7085 abolished the induction of all the chemokines regulated by MDA-MB-231 CM. This was confirmed by another approach, using a dominant negative form of IкB. We also observed that MDA-MB-231 CM was able to promote a NF- $\mathrm{KB}$ gene expression signature and to enhance p65 translocation. In search of the factors produced by metastatic cells that could enhance chemokine production by MSCs, we identified IL- $1 \beta$ as a potent NF- $\mathrm{KB}$ regulator that was produced at higher levels by the metastatic breast cancer cells compared to the non-metastatic cell lines. Similarly to MDA-MB-231 $\mathrm{CM}$, recombinant IL-1 $\beta$ or MCF-7 transfected with IL$1 \beta$ cDNA were able to induce the expression of the same chemokines CXCL1, 3, 5, 6, 8, CCL2 and CCL5 in the MSCs. Moreover, we showed that the inhibition of the secretion of IL- $1 \beta$ by MDA-MB-231 is sufficient to reduce at least in part the production of chemokines by the MSCs that have been stimulated by the MDA-MB-231 conditioned medium. These data demonstrate that IL-1 $\beta$ is one of the regulators responsible for the production of chemokines by MSCs in response to metastatic breast cancer cells. However, as IL-1 $\beta$ silencing in MDAMB-231 cells does not completely abolish the induction of chemokines in MSCs, we cannot exclude that other factors than IL- $1 \beta$ can be released by metastatic breast cancer cells and could be involved in the stimulation of MSCs. The identification of soluble factors produced by cancer cells that could change MSC behavior is just starting. Another study has also identified IL-1 as a factor released by cancer cells that could affect the behavior of MSCs [42]. Different groups have also identified osteopontin, Insulinlike-Growth Factor-1 (IGF-1) or the pro-inflammatory peptide LL-37 as possible secreted factors by cancer cells, which could increase CCL5 levels in MSCs [4345]. In the same line, the chemokines CCL 2 or CCL25 produced by cancer cells could be attractant for MSCs and explain their tropism for tumor sites $[9,33]$. What will be the consequence of the presence of MSCs in tumors and of an enhanced secretion of chemokines by MSCs? We believe that a vicious circle could take place, with first, the production of factors by aggressive breast cancer cells, which will enhance the production of chemokines by MSCs and then the action of these chemokines on the tumor cells themselves or on other cells of the tumor microenvironment. We observed that the conditioned medium of MSCs that have been stimulated by the conditioned of MDA-MB-231-shIL-1 $\beta$ cells is less potent to promote the migration of MDA-MB-231 cells than the one of wild-type MDA-MB-231 cells. This confirms the hypothesis that factors, and in particular chemokines released by MSCs upon stimulation by metastatic breast cancer cells, can enhance the aggressiveness of cancer cells (Figure 5). Multiple chemokines have been shown to promote tumor growth, cell invasion or metastasis or to be expressed at higher levels in metastasis sites compared to the primary tumor $[21-23,25]$. It was shown that chemokines produced by adipose tissue derived stromal cells (ADSC), that have close properties with BM-MSCs, can enhance the proliferation of cancer cells [46]. Based on the identification of MSCs in human ovarian tumors, McLean et al. showed that MSCs could enhance tumor growth by increasing the number of cancer stem cells [15]. It is worthwhile noting that several chemokines identified in our screen have angiogenic properties. This is in particular the case for CXCL1, 2, 3, 5, 6 or 8, that are ELR-positive CXC chemokines [47] and could increase endothelial cell proliferation. Corcoran et al. have also reported the ability of MSCs to facilitate trans-endothelial migration of breast cancer cells and in turn bone marrow entry through the production of SDF-1/CXCL12 [31]. All these stimulations of MSCs with tumor cells could thus have adverse effects on the outcome of the patients.

Overall, our data suggest that a complex dialog occurs between MSCs and breast cancer cells, which is strongly associated with the metastatic potential of the breast cancer cells (Figure 6). This could have important consequences in terms of understanding the beneficial or adverse actions of MSCs on cancer progression

\section{MATERIALS AND METHODS}

\section{Cell culture}

MDA-MB-231, MCF-7, MDA-MB-436 and BT-474 breast cancer cells lines were purchased from ATCC and maintained in DMEM-F12 supplemented with $10 \%$ Fetal Calf Serum (FCS) and gentamycin as previously described [48].

Human Bone marrow mesenchymal stem cells were isolated at EFS- (Etablissement Français du Sang) -Pyrénées-Méditerranée (Toulouse) from healthy donors $(n=5)$. This French institution prepares MSCs for therapeutic uses.

Briefly, bone marrow cells were harvested from filters used during the processing of allogeneic bone marrow transplantation. They were counted and seeded, without further purification, at $5 \times 10^{4}$ nucleated cells $/ \mathrm{cm}^{2}$ in 
$\alpha$-minimal essential medium ( $\alpha$-MEM) supplemented with $10 \%$ fetal calf serum (FCS) and ciprofloxacin $(10 \mu \mathrm{g} / \mathrm{ml})$. After 21 days they were harvested using trypsin and cultured at $10^{3}$ cells $/ \mathrm{cm}^{2}$ in the same medium for 21 days. They were then frozen until expanded for the experiments. According to quality standards of ISCT (International Society for Cell Therapy) [49], each lot of MSC were adherent cells that express CD73, CD90 and CD105 for more than $95 \%$ of the cells and did not express CD34, CD45, CD14 and CD19. All MSC cell lines used in this study were able to differentiate in osteoblastic and adipogenic lineages.

To prepare conditioned medium from breast cancer cells and MSCs, cells at 70\% confluency were grown in $\alpha$-MEM with $10 \%$ FCS and harvested after 48 h. Control media were incubated in the same conditions. The medium was collected from the dishes, centrifuged $10 \mathrm{~min}$ at 1500 rpm to eliminate residual cells and the supernatant was then frozen at $-80^{\circ} \mathrm{C}$ until use for ELISA or treatment of the cells. Treatments with Bay 11-7085 (Biotrend Chemicals AG, Zurich, Switzerland), were performed at a concentration of $10 \mu \mathrm{M}$ and were started one hour before addition of conditioned medium.

\section{Silencing of IL-1 $\beta$}

The stably transfected MDA-MB-231-shIL-1 $\beta$ cell line was obtained after transfection (as previously described [50]) with the plasmid pLKO1 - ShRNA hIL-1 $\beta$ TRCN0000058385 NM_000576.2-148 (Sigma-Aldrich, Saint-Quentin Fallavier, France), which binds to IL$1 \beta$ mRNA. Control cells were transfected with empty pLKO1-shRNA vector or with scramble shRNA (SHC002, Sigma-Aldrich, Saint-Quentin Fallavier, France). Transfected cells were then selected by puromycin at a concentration of $5 \mu \mathrm{g} / \mathrm{ml}$. Pools of cells clones were isolated and tested for IL-1 $\beta$ repression.

\section{Transfection of IL-1 $\beta$}

MCF-7 cells were plated in $10 \mathrm{~cm}$ dishes and transfected using JetPEI (Ozyme, St Quentin Yvelines, France) according to the manufacturer's recommendations, using $10 \mu \mathrm{g}$ of pUNO (control vector) or pUNO-hIL1 $\beta$ expression vector (Invivogen, Toulouse, France). After $18 \mathrm{~h}$ incubation, the medium was removed and the cells were placed into a fresh medium. Fourty eight hours later, conditioned medium was harvested. The medium was collected from the dishes, centrifuged $10 \mathrm{~min}$ at $1500 \mathrm{rpm}$ to eliminate residual cells and the supernatant was then frozen at $-80^{\circ} \mathrm{C}$ until use.

\section{Recombinant adenovirus IKB DN infection}

The adenoviruses Ad5 (empty backbone) and dominant negative I $\mathrm{B}$ DN ( $\mathrm{I} \kappa \mathrm{B}(\mathrm{SA}) 2$, with $\mathrm{S} 32 \mathrm{~A}$ and S36A mutations) have been described previously [36, 51]. MSCs cells were infected overnight at a multiplicity of infection (MOI) of 100 with Ad5 or Ad- I $\mathrm{B}$ DN adenoviruses in DMEM/F12 10\% FCS. The next day, the medium was changed and the cells were treated with control medium or conditioned medium from MDAMB-231 cells. After 6 h, RNA was extracted from MSCs.

\section{RNA extraction and reverse transcriptase, quantitative PCR}

Total RNA was isolated using TRIzol reagent (Invitrogen, Cergy Pontoise, France), as described by the manufacturer. Reverse transcription was performed with $1 \mu \mathrm{g}$ of total RNA using random primers and with M-MLV enzyme (Invitrogen, Cergy Pontoise, France). Real time quantitative PCR was realized with SYBR green Master Mix (Roche, Meylan, France), on a Light Cycler 480 instrument (Roche, Meylan, France) as previously described [23]. Ribosomal protein S9 (rS9) was used as an internal control, except for Figure 5 in which TBP was used as internal control. The sequence of the primers used in this study is indicated in Supplementary Table $\mathrm{S} 1$. Results are expressed as $\mathrm{N}$-fold differences in target gene expression relative to the internal control gene and termed "mRNA expression", were determined as mRNA expression $=2^{\Delta \mathrm{Ctsample}}$, where the $\Delta \mathrm{Ct}$ value of the sample was determined by subtracting the $\mathrm{Ct}$ value of the target gene from the $\mathrm{Ct}$ value of the internal control gene. Target genes were considered to be not detectable when the $\mathrm{Ct}$ value was above 35 .

\section{Immunofluorescence for p65}

MSCs were plated $48 \mathrm{~h}$ before and, washed with PBS and incubated with control medium, cancer cellconditioned media or TNF- $\alpha(1 \mathrm{ng} / \mathrm{ml})$, for $30 \mathrm{~min}$ and $2 \mathrm{~h}$. Cells were fixed with paraformaldehyde (3.2\%) for $20 \mathrm{~min}$ and permeabilized with MetOH $100 \%$ for $10 \mathrm{~min}$. Immunofluorescence detection of p65 was performed with rabbit anti-p65 (Santa Cruz, SC-372, 1/300) and FITC-conjugated anti-rabbit antibodies (goat anti-rabbit IgG, Life Technologies, 1/100). Hoechst 33342 (Life Technologies, Saint Aubin, France) was used for nuclei staining. Imaging of the immunofluorescence staining was done with a Zeiss AxioImagerZ1/Apotome (MRI platform, Montpellier, France). Homogenous cell fields were chosen on the basis of the Hoechst staining prior to shifting to the p65-FITC imaging. All digitalized images were mounted with the Adobe Photoshop software.

\section{Nuclear extracts preparation and western blotting}

For nuclear cell extracts, cells were centrifuged and pellets were resuspended in buffer A (10 mM Hepes pH 7.9, $10 \mathrm{mM} \mathrm{KCl,} \mathrm{1mM} \mathrm{EDTA,} \mathrm{0,} \mathrm{5 \%} \mathrm{NP-40)}$ supplemented with protease inhibitor cocktail (Roche, Meylan, France) and incubated on ice for $15 \mathrm{~min}$ and 
then centrifuged $\left(30 \mathrm{sec}, 12000 \mathrm{~g}, 4^{\circ} \mathrm{C}\right)$. Pelleted nuclei were resuspended in buffer B (20 mM Hepes pH 7.9, $0.4 \mathrm{M} \mathrm{NaCl}, 1 \mathrm{mM}$ EDTA) supplemented with protease inhibitor cocktail, incubated on ice for $20 \mathrm{~min}$ and lysed by 3 freezing- defreezing cycles (liquid nitrogen $/ 37^{\circ} \mathrm{C}$ ) and then centrifuged (10 $\left.\mathrm{min}, 13000 \mathrm{rpm}, 4^{\circ} \mathrm{C}\right) .20 \mu \mathrm{g}$ of protein extracts were subjected to SDS-PAGE protein samples Western blot analyses were done using p65 (Santa Cruz, SC-372, 1/1000) and Histone H3 (Santa Cruz, sc10809, 1/200) antibodies. Immunoreactivity was detected with Millipore ECL system. Histone H3 was used as a loading control.

\section{ELISA}

Chemokine concentration in culture supernatants was determined by ELISA with CXCL1, CXCL6, CXCL8 (DY208) and CCL2 (DY279) Duoset kits (R\&D Systems, Minneapolis, MN) and CCL5 (900-K33) (Peprotech, Neuilly sur Seine, France) as recommended by the manufacturers [36]. For IL-1 $\beta$ ELISA, DY201 Duoset kit (R\&D Systems, Lille, France) was used, but horseradish peroxidase (HRP)-conjugated labels were detected with Lumina Forte (Millipore, Molsheim, France) and measurement performed on a Centro LB960 Berthold luminometer (Berthold, Thoiry, France).

\section{Wound healing experiments}

Conditioned medium from MSC was prepared by treating MSC cells for $24 \mathrm{~h}$ with conditioned medium from MDA-MB-231 or MDA-MB-231-shIL1 $\beta$ cancer cells. The medium was then replaced with fresh one and collected after $24 \mathrm{~h}$. The medium was centrifuged $10 \mathrm{~min}$ at $1500 \mathrm{rpm}$ to eliminate residual cells and the supernatant was frozen at $-80^{\circ} \mathrm{C}$ under further use.

MDA-MB-231 cells were plated in 12-well dishes in DMEM-F12 containing 10\% CDFCS. $24 \mathrm{~h}$ after plating, the cells were treated overnight with conditioned medium of MSCs. The next morning, wound induced migration was triggered by scraping the cells with a P1000 tip and the wound was pictured immediately. $6 \mathrm{~h}$ after the wound, the cells were pictured again. The $\%$ of wound filling was calculated by measuring on the pictures the remaining gap space.

\section{Statistics}

Statistical analyses were carried out using unpaired Student's $t$ test.

\section{ACKNOWLEDGMENTS}

PE was supported by ARTP, AC by SENESCYT, CB by INSERM Transfert, JS by Fondation de France and MB by ARC Fundation (Association pour la Recherche sur le Cancer). This work was supported by ARC Fundation and la Ligue contre le Cancer. We thank the MRI platform
(Montpellier) for technical help with microscopy. We are grateful to C. Timaxian for technical help. Sys2Diag is part of the GDR Micronit.

\section{CONFLICTS OF INTEREST}

The authors declare no conflict of interest.

\section{REFERENCES}

1. Hanahan D, Weinberg RA. Hallmarks of cancer: the next generation. Cell. 2000; 144:646-674.

2. Wels J, Kaplan RN, Rafii S, Lyden D. Migratory neighbors and distant invaders: tumor-associated niche cells. Genes Dev. 2008; 22:559-574.

3. Joyce JA, Pollard JW. Microenvironmental regulation of metastasis. Nat Rev Cancer. 2009; 9:239-252.

4. Lazennec G, Jorgensen C. Concise review: adult multipotent stromal cells and cancer: risk or benefit? Stem Cells. 2008; 26:1387-1394.

5. Mishra PJ, Mishra PJ, Humeniuk R, Medina DJ, Alexe G, Mesirov JP, Ganesan S, Glod JW, Banerjee D. CarcinomaAssociated Fibroblast-Like Differentiation of Human Mesenchymal Stem Cells. Cancer Res. 2008; 68:4331-4339.

6. Quante M, Tu SP, Tomita H, Gonda T, Wang SS, Takashi S, Baik GH, Shibata W, Diprete B, Betz KS, Friedman R, Varro A, Tycko B, Wang TC. Bone marrowderived myofibroblasts contribute to the mesenchymal stem cell niche and promote tumor growth. Cancer Cell. 2011; 19:257-272.

7. Kidd S, Spaeth E, Watson K, Burks J, Lu H, Klopp A, Andreeff M, Marini FC. Origins of the tumor microenvironment: quantitative assessment of adipose-derived and bone marrow-derived stroma. PLoS One. 2012; 7:e30563.

8. Shi Y, Su J, Roberts AI, Shou P, Rabson AB, Ren G. How mesenchymal stem cells interact with tissue immune responses. Trends Immunol. 2012; 33:136-143.

9. Dwyer RM, Potter-Beirne SM, Harrington KA, Lowery AJ, Hennessy E, Murphy JM, Barry FP, O’Brien T, KerinMJ. Monocyte chemotactic protein-1 secreted by primary breast tumors stimulates migration of mesenchymal stem cells. Clin Cancer Res. 2007; 13:5020-5027.

10. Kidd S, Spaeth E, Dembinski JL, Dietrich M, Watson K, Klopp A, Battula VL, Weil M, Andreeff M, Marini FC. Direct evidence of mesenchymal stem cell tropism for tumor and wounding microenvironments using in vivo bioluminescent imaging. Stem Cells. 2009; 27:2614-2623.

11. Reagan MR, Kaplan DL. Concise review: Mesenchymal stem cell tumor-homing: detection methods in disease model systems. Stem Cells. 2011; 29:920-927.

12. Klopp AH, Gupta A, Spaeth E, Andreeff M, Marini F 3rd. Concise review: Dissecting a discrepancy in the literature: do mesenchymal stem cells support or suppress tumor growth? Stem Cells. 2011; 29:11-19. 
13. Karnoub AE, Dash AB, Vo AP, Sullivan A, Brooks MW, Bell GW, Richardson AL, Polyak K, Tubo R, Weinberg RA. Mesenchymal stem cells within tumour stroma promote breast cancer metastasis. Nature. 2007; 449:557-563.

14. Djouad F, Bony C, Apparailly F, Louis-Plence P, Jorgensen C, Noel D. Earlier onset of syngeneic tumors in the presence of mesenchymal stem cells. Transplantation. 2006; 82:1060-1066.

15. McLean K, Gong $\mathrm{Y}$, Choi $\mathrm{Y}$, Deng $\mathrm{N}$, Yang $\mathrm{K}$, Bai S, Cabrera L, Keller E, McCauley L, Cho KR, Buckanovich RJ. Human ovarian carcinoma-associated mesenchymal stem cells regulate cancer stem cells and tumorigenesis via altered BMP production. J Clin Invest. 2011; 121:3206-3219.

16. Khakoo AY, Pati S, Anderson SA, Reid W, Elshal MF, Rovira II, Nguyen AT, Malide D, Combs CA, Hall G, Zhang J, Raffeld M, Rogers TB, Stetler-Stevenson W, Frank JA, Reitz M, et al. Human mesenchymal stem cells exert potent antitumorigenic effects in a model of Kaposi's sarcoma. J Exp Med. 2006; 203:1235-1247.

17. Maestroni GJ, Hertens E, Galli P. Factor(s) from nonmacrophage bone marrow stromal cells inhibit Lewis lung carcinoma and B16 melanoma growth in mice. Cell Mol Life Sci. 1999; 55:663-667.

18. Cousin B, Ravet E, Poglio S, De Toni F, Bertuzzi M, Lulka H, Touil I, Andre M, Grolleau JL, Peron JM, Chavoin JP, Bourin P, Penicaud L, Casteilla L, Buscail L, Cordelier P. Adult stromal cells derived from human adipose tissue provoke pancreatic cancer cell death both in vitro and in vivo. PLoS One. 2009; 4:e6278.

19. Ho IA, Toh HC, Ng WH, Teo YL, Guo CM, Hui KM, Lam PY. Human bone marrow-derived mesenchymal stem cells suppress human glioma growth through inhibition of angiogenesis. Stem Cells. 2012; 31:146-155.

20. Balkwill FR, Mantovani A. Cancer-related inflammation: common themes and therapeutic opportunities. Semin Cancer Biol. 2012; 22:33-40.

21. Lazennec G, Richmond A. Chemokines and chemokine receptors: new insights into cancer-related inflammation. Trends Mol Med. 2010; 16:133-144.

22. Ali S, Lazennec G. Chemokines: novel targets for breast cancer metastasis. Cancer Metastasis Rev. 2007; 26:401-420.

23. Bieche I, Chavey C, Andrieu C, Busson M, Vacher S, Le Corre L, Guinebretiere JM, Burlinchon S, Lidereau R, Lazennec G. CXC chemokines located in the 4q21 region are up-regulated in breast cancer. Endocr Relat Cancer. 2007; 14:1039-1052.

24. Chavey C, Bibeau F, Gourgou-Bourgade S, Burlinchon S, Boissiere F, Laune D, Roques S, Lazennec G. Estrogenreceptor negative breast cancers exhibit a high cytokine content. Breast Cancer Res. 2007; 9:R15.

25. Freund A, Chauveau C, Brouillet JP, Lucas A, Lacroix M, Licznar A, Vignon F, Lazennec G. IL-8 expression and its possible relationship with estrogen-receptor-negative status of breast cancer cells. Oncogene. 2003; 22:256-265.

26. Boissiere-Michot F, Lazennec G, Frugier H, Jarlier M, Roca L, Duffour J, Du Paty E, Laune D, Blanchard F, Le Pessot F, Sabourin JC, Bibeau F. Characterization of an adaptive immune response in microsatellite-instable colorectal cancer. Oncoimmunology. 2014; 3:e29256.

27. Mantovani A. Cancer: Inflaming metastasis. Nature. 2009; 457:36-37.

28. Zlotnik A, Burkhardt AM, Homey B. Homeostatic chemokine receptors and organ-specific metastasis. Nat Rev Immunol. 2011; 11:597-606.

29. Vindrieux D, Escobar P, Lazennec G. Emerging roles of chemokines in prostate cancer. Endocr Relat Cancer. 2009; 16:663-673.

30. Anton K, Banerjee D, Glod J. Macrophage-associated mesenchymal stem cells assume an activated, migratory, proinflammatory phenotype with increased IL-6 and CXCL10 secretion. PLoS One. 2012; 7:e35036.

31. Corcoran KE, Trzaska KA, Fernandes H, Bryan M, Taborga M, Srinivas V, Packman K, Patel PS, Rameshwar P. Mesenchymal stem cells in early entry of breast cancer into bone marrow. PLoS One. 2008; 3:e2563.

32. Menon LG, Picinich S, Koneru R, Gao H, Lin SY, Koneru M, Mayer-Kuckuk P, Glod J, Banerjee D. Differential gene expression associated with migration of mesenchymal stem cells to conditioned medium from tumor cells or bone marrow cells. Stem Cells. 2007; 25:520-528.

33. Xu S, Menu E, De Becker A, Van Camp B, Vanderkerken K, Van Riet I. Bone marrow-derived mesenchymal stromal cells are attracted by multiple myeloma cell-produced chemokine CCL25 and favor myeloma cell growth in vitro and in vivo. Stem Cells. 2012; 30:266-279.

34. Ren G, Zhao X, Wang Y, Zhang X, Chen X, Xu C, Yuan ZR, Roberts AI, Zhang L, Zheng B, Wen T, Han Y, Rabson AB, Tischfield JA, Shao C, Shi Y. CCR2-dependent recruitment of macrophages by tumor-educated mesenchymal stromal cells promotes tumor development and is mimicked by TNFalpha. Cell Stem Cell. 2012; 11:812-824.

35. Chaturvedi P, Gilkes DM, Wong CC, Luo W, Zhang H, Wei H, Takano N, Schito L, Levchenko A, Semenza GL. Hypoxia-inducible factor-dependent breast cancermesenchymal stem cell bidirectional signaling promotes metastasis. J Clin Invest. 2013; 123:189-205.

36. Chavey C, Muhlbauer M, Bossard C, Freund A, Durand S, Jorgensen C, Jobin C, Lazennec G. Interleukin-8 expression is regulated by histone deacetylases through the nuclear factor-kappaB pathway in breast cancer. Mol Pharmacol. 2008; 74:1359-1366.

37. Wang H, Cao F, De A, Cao Y, Contag C, Gambhir $\mathrm{SS}$, Wu JC, Chen X. Trafficking mesenchymal stem cell engraftment and differentiation in tumor-bearing mice by bioluminescence imaging. Stem Cells. 2009; 27:1548-1558. 
38. Spaeth EL, Dembinski JL, Sasser AK, Watson K, Klopp A, Hall B, Andreeff M, Marini F. Mesenchymal stem cell transition to tumor-associated fibroblasts contributes to fibrovascular network expansion and tumor progression. PLoS One. 2009; 4:e4992.

39. Djouad F, Plence P, Bony C, Tropel P, Apparailly F, Sany J, Noel D, Jorgensen C. Immunosuppressive effect of mesenchymal stem cells favors tumor growth in allogeneic animals. Blood. 2003; 102:3837-3844.

40. Ponte AL, Marais E, Gallay N, Langonne A, Delorme B, Herault $\mathrm{O}$, Charbord $\mathrm{P}$, Domenech J. The in vitro migration capacity of human bone marrow mesenchymal stem cells: comparison of chemokine and growth factor chemotactic activities. Stem Cells. 2007; 25:1737-1745.

41. Chamberlain G, Wright K, Rot A, Ashton B, Middleton J. Murine mesenchymal stem cells exhibit a restricted repertoire of functional chemokine receptors: comparison with human. PLoS One. 2008; 3:e2934.

42. Li HJ, Reinhardt F, Herschman HR, Weinberg RA. Cancerstimulated mesenchymal stem cells create a carcinoma stem cell niche via prostaglandin E signaling. Cancer Discov. 2012; 2:840-855.

43. Coffelt SB, Marini FC, Watson K, Zwezdaryk KJ, Dembinski JL, LaMarca HL, Tomchuck SL, Honer zu Bentrup K, Danka ES, Henkle SL, Scandurro AB. The pro-inflammatory peptide LL-37 promotes ovarian tumor progression through recruitment of multipotent mesenchymal stromal cells. Proc Natl Acad Sci U S A. 2009; 106:3806-3811.

44. Mi Z, Bhattacharya SD, Kim VM, Guo H, Talbot LJ, Kuo PC. Osteopontin promotes CCL5-mesenchymal stromal cell-mediated breast cancer metastasis. Carcinogenesis. 2011; 32:477-487.

45. Makinoshima H, Dezawa M. Pancreatic cancer cells activate CCL5 expression in mesenchymal stromal cells through the insulin-like growth factor-I pathway. FEBS Lett. 2009; 583:3697-3703.

46. Kucerova L, Kovacovicova M, Polak S, Bohac M, Fedeles J, Palencar D, Matuskova M. Interaction of human adipose tissue-derived mesenchymal stromal cells with breast cancer cells. Neoplasma. 2011; 58:361-370.

47. Strieter RM, Burdick MD, Gomperts BN, Belperio JA, Keane MP. CXC chemokines in angiogenesis. Cytokine Growth Factor Rev. 2005; 16:593-609.

48. Freund A, Jolivel V, Durand S, Kersual N, Chalbos D, Chavey C, Vignon F, Lazennec G. Mechanisms underlying differential expression of interleukin- 8 in breast cancer cells. Oncogene. 2004; 23:6105-6114.

49. Dominici M, Le Blanc K, Mueller I, Slaper-Cortenbach I, Marini F, Krause D, Deans R, Keating A, Prockop D, Horwitz E. Minimal criteria for defining multipotent mesenchymal stromal cells. The International Society for Cellular Therapy position statement. Cytotherapy. 2006; 8:315-317.

50. Bossard C, Busson M, Vindrieux D, Gaudin F, Machelon V, Brigitte M, Jacquard C, Pillon A, Balaguer P, Balabanian K, Lazennec G. Potential role of estrogen receptor beta as a tumor suppressor of epithelial ovarian cancer. PLoS One. 2012; 7:e44787.

51. Lucas A, Kremer EJ, Hemmi S, Luis J, Vignon F, Lazennec G. Comparative transductions of breast cancer cells by three DNA viruses. Biochem Biophys Res Commun. 2003; 309:1011-1016. 